\title{
COMPARISON OF TWO MICROWAVE DRYING TECHNIQUES FOR CEREAL SEEDS AND DETERMINATION OF THEIR PHYSICAL PARAMETERS
}

\author{
Petru Marian CÂRLESCU ${ }^{1, *}$, Marius BĂETU ${ }^{1}$, \\ Virginia CIOBANU², Ioan T,ENU ${ }^{1}$, Radu ROȘCA ${ }^{1}$ \\ *E-mail: pcarlescu@uaiasi.ro
}

Received: Nov. 10, 2021. Revised: Nov. 22, 2021. Accepted: Nov. 24, 2021. Published online: Dec. 7, 2021

\begin{abstract}
The microwave drying of wheat and corn seeds by two technologies at different working powers is studied here. The main objective is to evaluate the effect of microwaves on variations in the moisture, colour and size of the seeds after microwave drying. The tests are performed in microwave ovens with and without inverter technology at three drying powers $(260,440$ and $620 \mathrm{~W})$. It has been observed that increasing drying power results in a $\sim 50 \%$ reduction in drying time and a seed moisture level below 14\%. The colour variation of the seeds is insignificant between microwave drying with and without the inverter. However, there is also an unacceptable decrease in size for both types of seeds with increasing drying power, which can lead to increased shrinkage of the seeds and the appearance of cracks, especially in the corn seeds.
\end{abstract}

Keywords: microwave, drying, cereal seeds.

\section{INTRODUCTION}

Corn and wheat are of "great economic importance worldwide not only as human food, but also as animal feed and as a raw material for a large number of industrial products and biofuels" (García-Lara et al., 2019).

In order to be stored safely, avoiding the processes of respiration, germination, mould damage or insect infestation, corn and wheat seeds must be dried immediately after harvest. To "prevent the production of mycotoxins, drying is recommended immediately after harvest" (Chulze, 2010). Controlling the drying and storing of seeds is critical, as poor management at this point can result in significant financial losses for farmers.

Corn and wheat seeds can be dried either naturally or mechanically. Until the industrialisation of

\footnotetext{
1 University of Life Sciences "Ion lonescu de la Brad", lasi

${ }^{2}$ College of Agriculture and Food Industry „Vasile Adamachi”, lași
} 
agriculture, the most common form of drying utilized by farmers was natural drying. This method is difficult to apply for the drying of large quantities of cereals due to the long drying period required and also the variation of temperature and natural conditions during drying.

There have been several types of dryers designed for drying grain seeds (Barrozo, 2014; Bala, 2016; Bern et al., 2019). However, none of them have proven to be sufficient in meeting all of the seed's demands and drying requirements. The main systems for drying cereal seeds are solar, serial or continuous flow (Bala, 2016).

"The dryers most commonly used for drying seeds are fixed bed dryers (batch) and sliding bed dryers, in their various configurations (concurrent, countercurrent and cross-flow)" (Barrozo, 2014; Bala, 2016).

"One of the first types of dryers used for drying corn and wheat seeds was the forced air dryer and many different innovative models for drying forced air seeds have evolved in response to the needs of grain producers and processors" (Bern et al., 2019).

Over $85 \%$ of food-processing dryers are convective (Ashtiani et al., 2020), the heat required to reduce humidity by evaporation being provided with hot air.

Hot-air drying is adaptable, lowcost, and simple to implement, and the necessary equipment is fairly priced. This sort of dryer, on the other hand, has the primary drawback of requiring a lot of thermal energy for drying the grains.
Unfortunately, the limited
thermal conductivity of food components is another convective drying limiting issue. A rise in temperature can speed up the drying process, but it also causes physiologically active components to degrade.

It's critical to keep temperature and humidity under control during the drying process because both are necessary for seed viability. Depending on the variety tested, most authors believe temperatures above $50^{\circ} \mathrm{C}$ to be hazardous to seed viability (Navratil et al., 1984). There have been studies on the effect of high temperatures on soybean drying (Coradi et al., 2016). Moreover, the "drying temperature has a significant effect on mechanical properties" (Abasi et al., 2014) and can produce stress cracks or core rupture in seeds, resulting in mechanical damage (Mahiuddin et al., 2018; Mason et al., 2002). Therefore, temperature control must be considered when it is desired to develop a new drying process as an alternative to natural drying or convective processes. In this aspect, microwave drying has a lot of potential, because "this technique allows a good control of the process temperature, an increase of energy efficiency and a reduction of its carbon footprint" (Moreno et al., 2018; Schiffmann, 2015; Rattanadecho et al., 2016).

As the interior temperature of the materials rises to the water boiling point, the internal pressure of the products reaches significant levels 
(Ashtiani et al., 2018; Reyes et al., 2007; Swain et al., 2012).

Increasing vapor pressure allows water molecules to migrate to the materials surface, which increases the drying rate compared to the convective drying process (Song et al., 2017), which transfers heat to the inner sections of the materials.

"Previous studies on the drying of cereal seeds in the microwave have shown their effectiveness as a drying method" (Nair et al., 2011; Gürsoy et al., 2013), "although it should be noted that process parameters, especially temperature, play a very important role in determining the properties and the quality of these cereals" (Nair et al., 2011).

Consequently, the major goal of this study is to evaluate the effect of physical changes on seeds produced by microwave drying by two technologies, namely, by intermittent microwave power (without an inverter) and by introducing fixed microwave power (with an inverter) into the product at three different powers. The time required for drying the seeds decreases with increasing microwave power and we achieve the moisture required for seed preservation without the formation of cracks.

\section{MATERIALS AND METHODS}

\section{Materials}

The cereal seeds used in this study were common wheat, Triticum aestivum, and corn, Losc, which were purchased from farmers in the NE region of Romania. The seeds to be dried underwent a conditioning treatment so that they were clean and free of impurities.

\section{Equipment and process for drying}

In order to dry the grain seeds was used a Sharp R-200 microwave oven without inverter technology (intermittent microwave power), with an $800 \mathrm{~W}$ magnetron antenna using a frequency of $2.45 \mathrm{GHz}$ and a supply voltage of $220 \mathrm{~V}$, and a Panasonic microwave oven with inverter technology (fixed microwave power), with an $800 \mathrm{~W}$ magnetron using the same frequency and supply voltage (Fig. 1). The powers at which the drying of the corn and wheat seeds was achieved by both technologies were 260, 440 and $620 \mathrm{~W}$. The microwave powers for the two technologies and the drying time of the seeds were chosen so that their temperature did not exceed $55^{\circ} \mathrm{C}$.

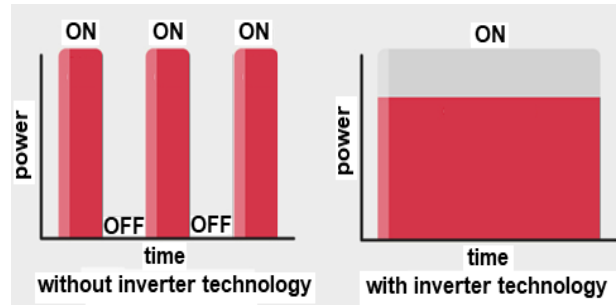

Figure 1 - Plots of time versus power for the two microwave drying technologies

\section{Calibration of microwave ovens}

According to the instructions of the manufacturers of the two microwave ovens, the output power of the magnetron was $800 \mathrm{~W}$. At $100 \%$ operation, the output microwave power was equal to $800 \mathrm{~W}$ of the thermal energy emitted at a frequency of $2.45 \mathrm{GHz}$. In reality, for the three chosen powers $(260,440$ and $620 \mathrm{~W})$ inside the oven, the microwave power was reduced as a result of energy absorption and operating losses. Calibration was required to obtain the power levels absorbed in the microwaves (Buffler, 1993).

To calibrate each microwave oven, two glasses were each filled with $1 \mathrm{~L}$ of deionized distilled water. The glasses were 
initially at room temperature and the initial water temperature was $20 \pm 2{ }^{\circ} \mathrm{C}$, measured after the water was introduced into the glasses and before being introduced into the microwave oven. The glasses were arranged in the oven's center, side by side across the cavity's width and touching. The oven was switched on for $122 \mathrm{~s}$. After the glasses were removed from the oven, the final temperatures were measured using a T-type thermocouple, the values being recorded with the date logger TC08PicoTech (UK).

The power was calculated from:

$$
P(W)=70 \times\left(\frac{\Delta T_{1}\left({ }^{\circ} \mathrm{C}\right)-\Delta T_{2}\left({ }^{\circ} \mathrm{C}\right)}{2}\right)
$$

where, $\Delta T_{1}$ and $\Delta T_{2}$ are the temperature increases of the water in the two glasses, which are computed by subtracting the initial and final water temperatures. The power of the oven is established with the average of three values of the measured power. When differences greater than $5 \%$ were recorded in the individual measurements, the entire test was repeated. The microwave ovens were preheated by heating $2 \mathrm{~L}$ of water for 5 min and the oven dish on which the glasses was placed was then wiped with a cold damp cloth. A plastic spoon was used to thoroughly mix the water in each vessel before measuring the initial and final temperatures at a resolution of $0.1{ }^{\circ} \mathrm{C}$.

The average values for the absorbed microwave powers corresponding to the power settings of 260, 440 and $620 \mathrm{~W}$ were observed as $232 \pm 5,370 \pm 6$ and $498 \pm 15 \mathrm{~W}$, respectively.

For the drying experiments with the two technologies, ten samples of wheat and ten samples of corn with $20 \mathrm{~g}$ per sample were selected, with a moisture content between 21 and 22\% (wb). All samples were placed in the microwave in glass containers so that a uniform distribution of seeds was possible. The uncovered containers were arranged on the microwave oven plate with a radius of $157.5 \mathrm{~mm}$. The drying experiments performed by the two technologies were repeated three times for both wheat and corn.

\section{Determination of humidity}

The humidity of the samples on a wet basis $\left(\mathrm{H}_{\mathrm{wb}}, \%\right)$ was established as the difference between the initial $\left(\mathrm{m}_{\mathrm{i}}\right)$ and the final $\left(m_{f}\right)$ mass of the analyzed seeds, respectively:

$$
H_{w b}=\frac{\left(m_{i}-m_{f}\right)}{m_{i}} \cdot 100
$$

An AGS60-T250 thermobalance with a capacity of $210 \mathrm{~g}$, a weighing resolution of $0.001 \mathrm{~g}$ and a moisture resolution of $0.01 \%$ was used to measure the moisture of cereal seeds before and after they were dried.

\section{Determination of colour variation}

Colour measurements were performed with a CIELAB colour space. The CIELAB colour value was determined using a D65 illuminant light source from a Volcraft RGB 2000 colorimeter. The colour space was displayed on the colorimeter in RGB values from $0-1023$ and then transformed using software into the parameters $L, a$ and $b$, where $L$ represents the colour brightness (a value of zero is black while 100 indicates white), $a$ represents the colour variation between green and magenta (green is represented by negative values, while magenta is represented by positive values) and $b$ represents the colour variation between blue (negative values) and yellow (positive values). To perform the colour determinations both before and after the seed drying, the colorimeter was calibrated using a white standard.

The total colour difference $(\Delta E)$ was calculated with the formula proposed by 
Vega-Galvez et al. (2012), before and after drying the cereal seeds:

$\Delta E=\sqrt{\left(L-L_{0}\right)^{2}+\left(a-a_{0}\right)^{2}-\left(b-b_{0}\right)^{2}}$

where, $L_{0}, a_{0}$ and $b_{0}$ are for the initial colour of the seeds and $L, a$ and $b$ are for the seed colour after drying.

\section{Determination of size variation}

The registration of the seed size was completed photometrically in a black box, so that the products did not contain shadows in the image. The seeds were placed on a matte cardboard with a ruler to calibrate the image and then photographed in high resolution. The registration of the photometric size of the cereal seeds was carried out both before and after drying using ImageJ software. The change in the size of the dried seeds appears as a contraction due to the elimination of the moisture content in the microwave drying process. The seed size variation was calculated as the variation of the surface area $(\Delta S)$ with the relation:

$$
\Delta S=S_{i}-S_{f}
$$

where, $S_{i}$ is the initial surface area of the seeds and the $S_{f}$ is their final surface area.

Simultaneously, with the determination of the size changes, the seeds were identified from the images of the seeds and their integrity changes as a result of the contractions suffered after drying (e.g., the appearance of cracks on their surface).

\section{RESULTS AND DISCUSSION}

The effects of drying wheat and maize seeds in microwave ovens utilizing two distinct technologies at three different power densities on drying time, humidity, color variation, seed size variation, and integrity are shown below. All experimental determinations were replicated three times.

The effect of microwave drying by generating intermittent microwave power on the physical parameters of the wheat and corn seeds was also investigated. The intermittent microwave drying method was performed with an intermittent power supply over a 20 s cycle (the microwave generator was turned off for $12 \mathrm{~s}$ and the generator was turned on for $8 \mathrm{~s}$ ). The average values for the absorbed microwave powers for seeds were 232,370 and $498 \mathrm{~W}$.

Two hundred grams of wheat seeds with a moisture content of $22 \%$ (wb) were used to study the intermittent microwave power drying process. The seeds were dried until their humidity reached $13.14 \%$ (wb) (Fig. 2). The drying time of the corn seeds, until they reached a humidity of $<14 \%$, varied depending on the power level from $5 \mathrm{~min}$ for $260 \mathrm{~W}, 4 \mathrm{~min}$ for $440 \mathrm{~W}$ and $2 \mathrm{~min}$ for $620 \mathrm{~W}$.

Two hundred grams of corn seeds with humidity content bof $21 \%$ were dried - under the same conditions as wheat seeds - until their humidity dropped to $13.56 \%$ (wb) (Fig. 2).

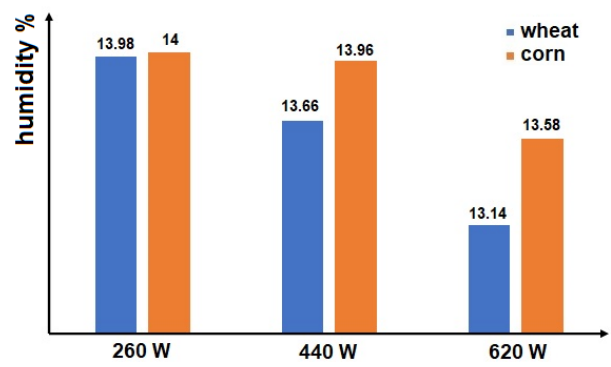

Figure 2 - Variation of humidity after drying the seeds at different powers without an inverter 
The drying time of the corn seeds, until they reached a humidity of $<14 \%$, varied depending on the power level from $6 \mathrm{~min}$ for $260 \mathrm{~W}, 4 \mathrm{~min}$ for $440 \mathrm{~W}$ and $3 \mathrm{~min}$ for $620 \mathrm{~W}$.

Another two hundred grams of wheat grains with a humidity of $21 \%$ were dried in fixed microwave power to a moisture content of $13.45 \%$ (wb) (Fig. 3).

The drying time of the corn seeds, until they reached a humidity of $<14 \%$, varied depending on the power level from $4 \mathrm{~min}$ for $260 \mathrm{~W}, 3 \mathrm{~min}$ for $440 \mathrm{~W}$ and $2 \mathrm{~min}$ for $620 \mathrm{~W}$.

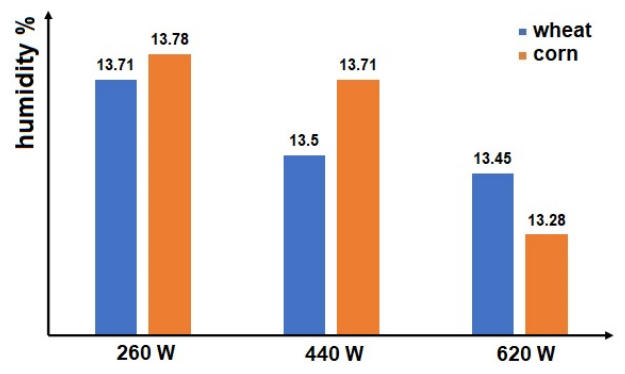

Figure 3 - Variation of humidity after drying the seeds at different powers with an inverter

The same amount of corn grains $(200 \mathrm{~g})$ with a moisture content of $22 \%$ was dried in fixed microwave power until their moisture was reduced to $13.28 \%(\mathrm{wb})$ (Fig. 3). The drying time of the corn seeds, until they reached a humidity $<14 \%$, varied depending on the power level from $5 \mathrm{~min}$ for $260 \mathrm{~W}$, $3 \mathrm{~min}$ for $440 \mathrm{~W}$ and $2 \mathrm{~min}$ for $620 \mathrm{~W}$.

The colour differences between the two methods of drying (with and without the inverter) are insignificant, instead they vary for the three powers of the microwave chosen for drying and also depending on the type of dried wheat or corn seeds (Fig. 4).

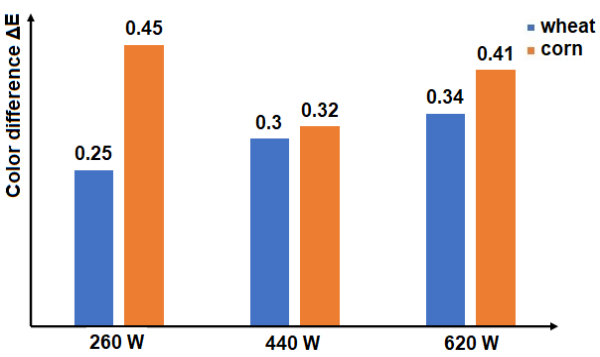

Figure 4 - Variation of colour after drying the seeds at different powers by both methods

A larger colour difference can be seen for the corn seeds at $260 \mathrm{~W}$, which can be explained by the slightly longer drying time of 5 or $6 \mathrm{~min}$, compared to the $2 \mathrm{~min}$ at $620 \mathrm{~W}$. It seems that in the wheat seeds, the colour of the seed surface changes less in the drying process at the three powers obtaining small colour changes, with the surface perhaps being more sensitive to colour changes with increasing microwave power when drying.

The changes in the size of wheat grains following the microwave drying process can be seen in Fig. 5 .

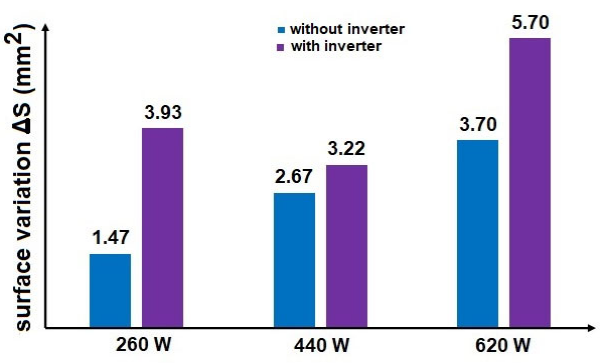

Figure 5 - Surface variation when drying wheat seeds at different powers 
The size changes were quantified by determining the surface changes of wheat and corn seeds that occur after drying. From Fig. 5, it can be seen that there is a greater change in the surface area of wheat seeds when microwave drying with the inverter technology compared to the non-inverter technology for all three powers considered in the experiment. However, for both drying technologies, an increase in these changes can be observed with increasing applied power. Excessive shrinkage of the wheat seeds during microwave drying with inverter technology led to cracks of more than $50 \%$ of the seeds dried at the three powers. Experimentally, it was found that when drying wheat without inverter technology, cracks appear in $10 \%$ of the dried seeds, when the surface variation exceeded $3 \mathrm{~mm}^{2}$ or when $620 \mathrm{~W}$ power was applied.

For corn seeds subjected to microwave drying by both technologies, it is observed that the surface area variation increases with increasing applied power (Fig. 6). The drying behaviour of these seeds is different from that of the wheat seed due to their different internal structure and harder and more brittle surface layer. At $620 \mathrm{~W}$ with inverter technology after $2 \mathrm{~min}$ of drying, it was observed that $80 \%$ of the seeds were cracked or had cracks on the outer surface, while with non-inverter technology, this decreased to $50 \%$.

At $440 \mathrm{~W}$ with inverter technology after a drying time of $3 \mathrm{~min}$, less than $10 \%$ cracked seeds were observed, while with non-inverter technology, no changes were observed on the outer surface. Increased power causes a rise in seed drying temperature, which has a substantial impact on the mechanical properties of the seed (Abasi etal., 2014), potentially causing stress cracking or kernel breaking (Mason et al., 2002).



Figure 6 - Surface variation when drying corn seeds at different powers

Optimisation of the applied power according to the type of seed to be dried, the drying time and the humidity before drying is therefore recommended.

\section{CONCLUSIONS}

Drying technology and applied power have an effect on the physical parameters in the microwave drying process for both wheat and corn seeds:

- An increase in applied power by both microwave drying technologies leads to a concomitantly decrease in drying time and moisture, with the moisture of preservability of the seeds obtained without the appearance of cracks in the seeds.

- Microwave drying with both technologies leads to dimensional changes through large surface variations as the applied drying power increases. 
- At high powers, the drying time is reduced, but this leads to contractions that occur in the seed that lead to increased internal stresses and cracks, respectively.

- Furthermore, through moisture loss, the external colour of wheat and corn seeds changes to darker shades, but these differences are not significant between the two technologies.

According to experiments, corn seeds are more sensitive to surface variations with increasing drying power than wheat seeds due to their structure.

Acknowledgements. This work was supported by a grant of the Romanian Ministry of Education and Research, project number CNCS/CCCDI-UEFISCDI, project number PN-III-P2-2.1-PED-20193001, within PNCDI III, contract no. 378PED/2020.s.

\section{REFERENCES}

Abasi, S. \& Minaee, S. (2014). Effect of drying temperature on mechanical properties of dried corn. Dry. Technol., 32(7): 774-780, DOI:10.1 080/07373937.2013.845203

Ashtiani, S.H.M., Rafiee, M., Morad, M.M., Khojastehpour, M., Khani, M.R., Rohani, A., Shokri, B. \& Martynenko, A. (2020). Impact of gliding arc plasma pretreatment on drying efficiency and physicochemical properties of grape. Innovative Food Sci. Emerg. Technol., 63, DOI: 10.1016/j.ifset. 2020.102381.

Ashtiani, S.H.M., Sturm, B. \& Nasirahmadi, A. (2018). Effects of hot-air and hybrid hot air-microwave drying on drying kinetics and textural quality of nectarine slices. Heat Mass
Transfer, 54: 915-927, DOI: 10.1007/ s00231-017-2187-0

Bala, B.K (2016). Drying and storage of cereal grains. 2nd Edition, WileyBlackwell.

Barrozo, M.A.S., Mujumda, A. \& Freir, J.T. (2014). Air-drying of seeds: a review. Dry. Technol., 32(10): 11271141, DOI:10.1080/07373937.2014. 915220

Bern, C.J., Quick, G \& Herum, F.L. (2019). Harvesting and postharvest management. In: Corn. Chem. Technol., 3rd Edition, S.O. SernaSaldivar (Ed.). Oxford, AACC International Press, Ch. 5, 109-145.

Buffler, C.R. (1993). Microwave cooking and processing, engineering fundamentals for the food scientist. Van Nostrand Reinhold, New York.

Chulze, S.N. (2010). Strategies to reduce mycotoxin levels in maize during storage: a review. Food Addit. Contam Part A Chem Anal Control Expo Risk Asses, 27(5): 651-657, DOI: 10.1080/19440040903573032

Coradi, P.C., Fernandes, C.H.P., Helmich, J.C. \& Goneli, A.L.D. (2016). Effects of drying air temperature and grain initial moisture content on soybean quality (Glycine $\max$ (L.) Merrill). Engenharia Agricola, 36(5): 866-876, DOI: 10.1590/1809-4430Eng.Agric.v3 6n5p866-876/2016.

García-Lara, S. \& Serna-Saldivar, S.O. (2019). Corn history and culture. In: Corn. Chem. Technol., 3rd Edition, S.O. Serna-Saldivar (Ed.). Oxford, ACC International Press, Ch. 1, pp. 1-18.

Gürsoy, S., Choudhary, R., Watson D.G (2013). Microwave drying kinetics and quality characteristics of corn. Int. J Agric. Biol. Eng., 6(1): 90-99.

Mahiuddin, Md., Khan, M.I.H., Kumar, C., Rahman, M.M. \& Karim, M.A. (2018). Shrinkage of food materials during drying: Current status and challenges. Compr. Rev. Food Sci. Food Saf., Institute of Food Technologists, 17: 1113-1126, DOI: 10.1111/1541-4337.12375 
Mason, S. \& D'croz-Mason, N. (2002). Agronomic practices influence maize grain quality, J. Crop Prod., 5(1-2): 75-91, DOI: 10.1300/J144v05n01_04

Moreno, Á.H., Hernández, Maqueda, R. \& Ballesteros, I. (2017). Secado industrial con energía microondas. In: Aplicaciones industriales del calentamiento con energía microondas, J.A. Menéndez, Á.H. Moreno (Eds.), Latacunga, Ecuador, Univ. Téc. de Cotopaxi, Ch. 5, 85-118.

Nair, G.R., Li, Z., Gariepy, Y. \& Raghavan, V. (2011). Microwave drying of corn (Zea mays L. ssp.) for the seed industry. Dry. Technol., 29(11): 1291-1296, DOI:10.1080/073 73937.2011.591715

Navratil, R.J. \& Burris, J.S. (1984). The effect of drying temperature on corn seed quality, Can. J. Plant Sci., 64(3): 487- 496, DOI: 10.4141/cjp s84-071

Reyes, A., Cerón, S, Zúñiga, R. \& Moyano, P. (2007). A comparative study of microwave-assisted air drying of potato slices. Biosyst Eng., 98(3): 310-318, DOI:10.1016/j.bio systemseng.2007.07.006

Rattanadecho, P. \& Makul, N. (2016). Microwave-assisted drying: a review of the state-of-the-art. Dry. Technol., 34(1): 1-38, DOI: 10.1080/07373937. 2014.957764

Schiffmann, R.F. (2015). Microwave and dielectric drying. In: Handbook of the Industrial Drying, 4th Edition, A.S. Mujumdar (Ed.), CRC Press, Boca Raton, FL., US, Ch. 13, 283-302.

Song, F, Li, Z. \& Raghavan, G.S.V. (2017). Combined microwave-hot air drying of burdock slices with feedback temperature control at surface and core. Dry. Technol.,35(14): 1781-1790, DOI: 10.1080/07373937. 2017.1279626

Swain, S., Samuel, D.V.K., Bal, L.M., Kar, A. \& Sahoo, G.P. (2012). Modeling of microwave assisted drying of osmotically pretreated red sweet pepper (Capsicum annuum L.). Food Sci. Biotechnol., 21(4): 969-978, DOI: 10.1007/s10068-012-0127-9 